\title{
Expectativas de educadores sobre a atuação do psicólogo escolar: relato de pesquisa
}

\author{
Luísa Evangelista Vieira Prudêncio \\ Universidade Federal de Santa Catarina - SC \\ Marivete Gesser \\ Universidade Federal de Santa Catarina - SC \\ Leandro Castro Oltramari \\ Universidade Federal de Santa Catarina - SC \\ Denise Cord \\ Universidade Federal de Santa Catarina - SC
}

\begin{abstract}
Resumo
O presente estudo teve como objetivo identificar as necessidades de intervenção profissional em Psicologia em escolas de uma capital do sul do país. Para a obtenção das informações, foram realizadas entrevistas semiestruturadas com 40 profissionais de 16 instituições de ensino, sendo essas escolas, creches e núcleos de educação infantil. A partir da análise das informações, identificaram-se três diferentes expectativas de atuação do psicólogo: a) o psicólogo como um profissional que atua na resolução de conflitos entre a família e a escola; b) o psicólogo como um profissional que atua no diagnóstico e no atendimento individual dos "alunos-problema", e c) o psicólogo como um profissional da prevenção e da promoção de saúde. O estudo mostrou que urge investir em uma formação de professores atenta à complexidade de elementos constituintes dos processos educativos e na formação de psicólogos preparados para se posicionarem na contracorrente das demandas medicalizantes.
\end{abstract}

Palavras-Chave: Psicologia escolar; atuação do psicólogo; formação de professores.

\section{Some educators expectations towards school psychology practice: a research report}

\begin{abstract}
This study aimed to identify the needs of professional intervention in psychology in schools of the southern capital. To obtain the information, semi-structured interviews were conducted with 40 professionals from 16 educational institutions, and these schools, kindergartens and early childhood centers. From the analysis of the information, identified three different psychologist's performance expectations: a) the psychologist as a professional engaged in the resolution of conflicts between family and school; b) the psychologist as a professional who works in the diagnosis and individual care of the "student-problem", and c) the psychologist as a professional prevention and health promotion. The study showed that there is an urgent need to invest in a teacher education attentive to the complexity of constituent elements of educational processes and training of psychologists prepared to take a stand against the current of medicalized demands.
\end{abstract}

Keywords: School psychology; psychologist performance; teaching work.

\section{Expectativas de educadores sobre la actuación del psicólogo escolar: relato de investigación}

\section{Resumen}

Es presente estudio tuvo como objetivo identificar las necesidades de intervención profesional en Psicología en escuelas de una capital del sur del país. Para la obtención de las informaciones, se realizaron entrevistas semiestructuradas con 40 profesionales de 16 instituciones de enseñanza, siendo esas escuelas, guarderías y núcleos de educación infantil. A partir del análisis de las informaciones, se identificaron tres distintas expectativas de actuación del psicólogo: a) el psicólogo como un profesional que actúa en la solución de conflictos entre la familia y la escuela; b) el psicólogo como un profesional que actúa en el diagnóstico y en la atención individual de los "alumnos-problema", y c) el psicólogo como un profesional de la prevención y de la promoción de salud. El estudio mostró que es urgente la necesidad de investirse en una formación de profesores atenta a la complexidad de elementos constituyentes de los procesos educativos y en la formación de psicólogos preparados para posicionarse en la contracorriente de las demandas medicalizantes.

Palabras-clave: Psicología escolar; actuación del psicólogo; formación de profesores. 


\section{Introdução}

A identificação das expectativas relacionadas à atuação profissional do psicólogo na escola é de grande importância para a implementação de ações nesta área que estejam em consonância com as necessidades sociais desse contexto. Por meio dessa identificação é possível contribuir com a formação do psicólogo a partir de uma perspectiva crítica de atuação profissional, voltada à promoção da cidadania e garantia dos direitos humanos (Gesser, 2013; Chagas, Pedroza,\& Branco, 2012).

A partir da identificação das expectativas de atuação profissional também é possível investigar qual é a perspectiva da demanda da psicologia escolar nas escolas. Neste sentido, é importante destacar que, na história da psicologia escolar brasileira, convivem dois enfoques distintos de atuação profissional.

Um desses enfoques, caracterizado por uma atuação profissional clínico-terapêutica do psicólogo escolar, tem como base o modelo médico. Neste, a atuação do psicólogo ocorre fora do espaço da escola, sendo centrada "na dimensão individual do educando e em seus 'problemas', atendendo, sobretudo, demandas específicas da escola, que encaminhava as crianças que tinham, a seu ver, 'problemas de aprendizagem' ou outras manifestações consideradas como 'distúrbios' inerentes ao próprio educando" (Antunes, 2008, p. 472).O modelo médico, na contemporaneidade, corrobora o crescente processo de patologização e medicalização da vida cotidiana e suas expressões contemporâneas no campo da educação escolar. Isso ocorre porque ele invisibiliza todas as questões sociais e políticas envolvidas no processo de escolarização, transformando as dificuldades escolares em doenças e transtornos do aluno (Guarido, 2010; Meira, 2012).

O outro enfoque de atuação profissional é ancorado em uma perspectiva aqui caracterizada como ético-política de educação, voltada à ampliação da aprendizagem e do desenvolvimento dos educandos e ao processo de humanização (Meira, 2003; Facci, 2009; Antunes, 2008). Esse enfoque tem como base a construção de processos educativos democráticos, os quais criem condições para que todos os educandos possam se apropriar dos conhecimentos produzidos pela humanidade ao longo da história (Antunes, 2008). Portanto, esse enfoque pode ser caracterizado como uma educação inclusiva das diferenças, sejam elas constituídas pelos marcadores de gênero, raça, classe social, religião, orientação sexual e deficiência.

Yamamoto, Santos, Galafassi, Pasqualini e Souza (2013) realizaram uma pesquisa com 108 psicólogos que atuavam em 25 Secretarias de Educação do estado de São Paulo com o objetivo de analisar as concepções e práticas desenvolvidas pelos psicólogos da rede pública frente às queixas escolares. Os resultados obtidos pelos autores evidenciaram que as práticas e as concepções dos psicólogos mesclam elementos centrados no enfoque clínico-terapêutico, com visões mais críticas sobre o processo de escolarização. No que se refere à atuação profissional, os autores identificaram três tendências de atuação, a saber: a) ten- dência clínica: caracterizada por uma atuação profissional individualizada e centrada no aluno, baseada no diagnóstico e tratamento de seus problemas de aprendizagem sem considerar as demais questões relacionadas ao processo de escolarização; b) tendência institucional: caracterizada pela atuação profissional centrada na escola como um todo, incluindo os diversos atores do contexto escolar, as relações de poder e as políticas educacionais; e c) tendência clínica e institucional: abarca atuações que reúnem características de ambas as tendências, situando-se em uma posição intermediária entre a tendência clínica e a institucional.

O presente estudo teve como objetivo identificar as necessidades de intervenção profissional em Psicologia nas escolas da rede municipal de ensino de uma capital do sul do país. A pesquisa foi solicitada pela Gerência de Formação Permanente, órgão vinculado à Secretaria Municipal de Educação, ao Laboratório de Psicologia Escolar e Educacional de uma universidade federal. Partiu-se do pressuposto de que a realização da pesquisa poderia contribuir para melhor direcionar a inserção de estagiários nas escolas da rede, bem como para o planejamento de ações futuras nestes campos de pesquisa e extensão.

Considera-se que a produção de conhecimentos na área da Psicologia Escolar e Educacional é de grande relevância para contribuir com a formação de profissionais preparados para atender a demanda escolar com base numa perspectiva crítica, rompendo com práticas a-históricas pautadas na psicologiadoescolar (Meira, 2000). Essas práticas - caracterizadas, segundo Souza (2004), Machado (2007) e Moysés e Collares (2010), pela psicologização e medicalização das queixas escolares - refletem uma visão liberal de homem e de mundo (Patto,1999) e contribuem com a reprodução de fenômenos como o fracasso escolar.

Acredita-se que a produção de conhecimentos neste campo do saber poderá contribuir para a construção de uma escola que consiga cumprir sua função social que, segundo autores como Facci (2009), Meira (2007) e Rego (2002), é a de possibilitar que os alunos se apropriem dos conhecimentos historicamente produzidos pela humanidade. As autoras destacam o papel da aquisição desses conhecimentos para o desenvolvimento das funções psicológicas superiores dos educandos e, portanto, para o processo de humanização.

A relevância da pesquisa está também na necessidade de se produzir conhecimento nesse âmbito de atuação, principalmente com a possível aprovação do projeto de lei PL N. 3688, de 2000, que dispõe sobre a prestação de serviços de psicologia e de assistência social nas escolas da redepública de educação básica. Se aprovada, esta lei poderá ser um dispositivo importante para a contratação deste serviço e consequentemente haverá um incremento nas ações dos psicólogos neste campo do conhecimento.Diante dessecenário, é de grande relevância saber o que os profissionais pensam sobre a atuação profissional do psicólogo.

Ainda no que se refere à inserção do psicólogo nas escolas da rede pública de ensino, o psicólogo já vem se inserindo via PSE - Programa Saúde na Escola. Este Programa foi instituído pelo decreto presidencial 6.286 de 
2007, como uma política intersetorial entre os Ministérios da Saúde e da Educação. Esta perspectiva vem ao encontro da atenção integral (prevenção, promoção e atenção) à saúde de crianças, adolescentes e jovens do ensino público, no âmbito das escolas e unidades básicas de saúde, realizadas pelas Equipes de Saúde da Família, segundo os princípios do SUS, e pelos profissionais da educação de forma integrada. Seu objetivo é o de propiciar ações de promoção à saúde previstas no Plano Nacional de Educação (PNE) a partir da operacionalização de cinco componentes: avaliação das condições de saúde (clínica e psicossocial); promoção da saúde e prevenção das doenças e agravos; educação permanente e capacitação de profissionais da Educação e Saúde e de jovens para o PSE; monitoramento e avaliação da saúde dos estudantes,e monitoramento e avaliação do PSE (Brasil, 2009).

A partir da inserção dos professores do Departamento de Psicologia da Universidade Federal em que a pesquisa foi realizada nas escolas e acompanhando ações do PSE, percebeu-se que, com a possibilidade de encaminhar demandas escolares às unidades básicas de saúde, os profissionais da educação têm explicitado expectativas de avaliação e atendimento clínico às dificuldades de aprendizagem. Esta expectativa encontra eco no fato de que há psicólogos trabalhando junto aos Núcleos de Atenção à Saúde da Família (NASF), os quais integram equipes da Estratégia de Saúde da Família (ESF), atuantes nas Unidades Básicas de Saúde (UBS) (Cord, Gesser, Nunes,\& Storti, 2015).

Considera-se que a produção de conhecimentos na área da Psicologia Escolar e Educacional é de grande relevância, pois persiste a necessidade de formar profissionais preparados para atender as queixas escolares numa perspectiva crítica, que de fato supere as práticas pautadas na patologização e medicalização dos fenômenos escolares (Meira, 2000). Mesmo nos dias de hoje é possível identificar práticas realizadas na escola por profissionais tanto da psicologia quanto de outras áreas, que atendem a uma visão liberal de homem e de mundo (Patto, 2009) e contribuem com a reprodução e a naturalização das queixas escolares.

Com o incremento das ações intersetoriais provenientes de políticas públicas de saúde, formar psicólogos que atentem para a produção da queixa escolar numa perspectiva crítica deixa de ser somente uma questão da disciplina de psicologia escolar nos currículos, constituindo-se em tema transversal à formação integral dos psicólogos. Cabral e Sawaya (2001) realizaram uma pesquisa junto a profissionais que atuam nos serviços públicos de saúde do município de Ribeirão Preto, com o objetivo de conhecer a atuação dos psicólogos diante dos encaminhamentos referentes às queixas escolares. Os resultados obtidos pelas autoras mostraram que esses profissionais ainda compreendiam a queixa escolar como um problema do aluno pobre e de sua família, passível de ser analisado e tratado fora do contexto escolar. Embora os entrevistados apontem a participação da escola na produção das dificuldades escolares, o foco de intervenção ainda é o atendimento individualizado dos alunos e dos seus familiares. As autoras destacam que, apesar dos avanços teórico-metodológicos presentes nas novas compreensões das queixas escolares, eles ainda não se fazem suficientemente presentes na atuação desses profissionais.

Em síntese, a realização desta pesquisa se justificou pela necessidade de conhecer as expectativas que os sujeitos da educação têm no que se refere ao trabalho do psicólogo e direcionar as ações de estágio com base nestas necessidades. Também possibilitou fazer uma análise crítica dessas expectativas, à luz de princípios voltados à garantia dos direitos humanos e à inclusão dos diferentes modos de existência no contexto escolar.

\section{Método}

Esta pesquisa refere-se a um levantamento de necessidades de intervenção profissional em Psicologia junto às escolas da rede pública de uma capital do sul do Brasil. O estudo foi realizado em parceria com a Gerência de Formação Permanente da Secretaria Municipal de Educação ao longo do ano de 2012.

O instrumento utilizado para a coleta das informações foi um roteiro de entrevista semiestruturada. Segundo Cruz Neto (2000), a entrevista semiestruturada, de modo focalizado, constitui um roteiro de tópicos relativos ao problema que se está estudando e o entrevistador tem a liberdade de incluir as perguntas que considerar necessárias ao longo da prática de entrevista. Esse procedimento possibilita a compreensão e o aprofundamento das questões que emergem da fala do sujeito, bem como a identificação de experiências sociais relevantes à compreensão do seu processo de constituição subjetiva.

Foram realizadas 40 entrevistas com profissionais da educação que atuam em 16 escolas da rede pública de ensino da capital pesquisada nas funções de professor, orientador pedagógico, diretor e auxiliar de ensino. As instituições de ensino nas quais eles atuam atendem alunos provenientes da educação infantil e do ensino fundamental. O contato com as escolas foi obtido mediante parceria com a Gerência de Formação Permanente que enviou uma relação com o nome das unidades educativas, nome da pessoa responsável e telefone para contato. Ademais, este estudo foi realizado de forma integrada às disciplinas Psicologia Escolar I e II do currículo de formação do psicólogo de um curso de psicologia de uma universidade federal, o que contribuiu para a integração entre as atividades de ensino, pesquisa e extensão, tanto para os docentes das mesmas quanto para os estudantes de psicologia.

Antes da realização das entrevistas, solicitou-se aos sujeitos que assinassem o Termo de Consentimento Livre e Esclarecido (TCLE). Neste, constavam as informações referentes aos objetivos e ao método de pesquisa, bem como se garantia que os dados pessoais dos participantes seriam resguardados e que eles teriam a possibilidade de retirar sua participação a qualquer momento do processo. Visando garantir o anonimato, foram atribuídos nomes fictícios aos participantes na divulgação dos resultados. 
Para o tratamento dos dados, utilizou-se a análise de conteúdo do tipo categorial, que, conforme Bardin (2000), remete a uma operação de "desmembramento do texto em unidades, em categorias segundo reagrupamentos analógicos" (Bardin, 2000, p. 153), o que possibilita a obtenção de temas significativos para a explicação do material coletado.

Os dados foram sistematizados em categorias para serem analisados qualitativamente de acordo com os conteúdos obtidos nas entrevistas. Após esta etapa, foram distribuídos em temas definidos a posteriori. Considerou-se, em acordo com Unrug (citado por Minayo, 2008, p. 315-316), que tema é "uma unidade de significação complexa, de comprimento variável, e sua validade não é de ordem linguística, mas antes de ordem psicológica. Pode constituir um tema tanto uma afirmação como uma alusão". A análise temática consistiu em descobrir os núcleos de sentido que compõem a comunicação cuja presença ou frequência signifique alguma coisa para o objetivo analítico visado (Minayo, 2008). A partir desta identificação dos sentidos de cada categoria, estas foram devidamente agrupadas e relacionadas com a teoria.

\section{Resultados e discussão}

A análise das informações obtidas a partir dos depoimentos dos educadores entrevistados indicou dois eixos centrais. Um deles aponta a compreensão do papel do psicólogo nas escolas a partir de uma perspectiva medicalizante, com a qual este profissional seria capaz de resolver as problemáticas presentes no contexto escolar de forma imediata. Nesse eixo, os depoimentos apontaram dois aspectos: a) o psicólogo como um profissional que atua na resolução de conflitos entre a família e a escola e b) o psicólogo como um profissional que atua no diagnóstico e no atendimento individual dos "alunos-problema".

O outro eixo de análise evidencia a compreensão do papel do psicólogo pelaótica daprevenção e da promoção de saúde. Nele foram agrupadas as falas voltadas ao aprimoramento dos processos educacionais no contexto escolar como um todo. Esse está ligado à expectativa do psicólogo como profissional da prevenção e da promoção de saúdepor meio da realização de um trabalho voltado à orientação e oferta de suporte emocional para a equipe pedagógica.

É importante destacar que alguns educadores apresentaram falas que corroboram os dois eixos de análise, evidenciando o atravessamento desses sujeitos,tanto por discursos voltados à individualização, patologização e medicalização das queixas escolares, quanto por discursos voltados à compreensão desses fenômenos com base em uma concepção crítica de educação e de psicologia.

\section{O psicólogo como um profissional que atua na resolução de conflitos entre a família e a escola}

Nesta unidade apresentar-se-á a compreensão de que o psicólogo tem o papel de mediador nos conflitos fami- liares presentes no cotidiano escolar, os quais são considerados pelos entrevistados um dos motivos geradores do fracasso escolar, da agressividade, da falta de disciplina e da falta de interesse por parte dos alunos. Para tanto, primeiramente será mostrado que os educadores tendem a explicar as dificuldades escolares como decorrentes de problemas familiares. Em seguida, será evidenciada a crença de que, ampliando-se a participação da família na escola, essas dificuldades poderiam ser solucionadas. Por fim, será dada visibilidade à ideia presente nas falas dos entrevistados de que o psicólogo é um profissional que poderá contribuir, a partir de uma perspectiva medicalizante, para a resolução das problemáticas relacionadas à família que, na concepção deles, têm sido as responsáveis pelas dificuldades escolares dos alunos.

Diversas falas que sustentam essa unidade de análise evidenciaram a compreensão da família como a responsável pelo desempenho dos alunos na escola. Quando estes não se enquadram exatamente naquilo que é esperado pela escola, esta tende a buscar, entre outras explicações, a de que o problema encontra-se na família, que não tem uma suposta "estrutura" para educar os filhos. O depoimento abaixo é representativo desse dado:

[...] às vezes é o pai, a mãe e isso acaba sendo despejado em cima do aluno e o aluno vai colocar essa válvula de escape onde? Na escola, no professor, nos colegas, depredando a escola, não estudando. Está aí uma série de conflitos (José, professor há 15 anos).

A pesquisa mostrou que este processo de culpabilização da família é muito recorrente nas falas dos professores. Esses atribuem à família os motivos geradores do fracasso escolar, da agressividade, da falta de disciplina e da falta de interesse por parte dos alunos.

A forma mais comum de responsabilização das famílias pelas dificuldades escolares dos alunos refere-se aos julgamentos decorrentes da não participação nas reuniões convocadas pela escola e demais momentos em que os pais e responsáveis são solicitados a comparecer. Objetivando ilustrar tal perspectiva, destaca-se a fala de Bárbara, professora há 20 anos:

A maior dificuldade que nós temos é com crianças que têm dificuldade e a família não participa muito. Por exemplo, a criança que tem dificuldade, agente chama e a família não tem oportunidade de vir. A família não tem muito esclarecimento, né?.

Esse processo de responsabilização da família pelas dificuldades escolares também foi identificado no estudo realizado por Ribeiro e Andrade (2006). No que se refere à participação dos pais na escola, os autores identificaram que os mecanismos disciplinares e discursivos cristalizados e estereotipados acabavam oprimindo os pais que não reproduzem as expectativas hegemônicas, fazendo-os desistirem e/ou se afastarem da escola. 
No que diz respeito à percepção sobre a atuação do psicólogo junto às famílias, entre os pontos mais citados destaca-se o de que o psicólogo deveria atuar na perspectiva da orientação, encaminhamento e mediação da relação entre a escola e a família e entre pais e filhos. Uma das formas como isso poderia ser feito refere-se à orientação da família quanto aos seus problemas, os quais acabam interferindo na vida dos filhos, conforme indica a fala de Claudia: “(...) orientações específicas do tipo sociais mesmo, desde a relação homem-mulher, adulto-criança, questões econômicas" (supervisora pedagógica de uma creche, atua na área da educação há 12 anos). A fala do José, professor há 15 anos,corrobora essa questão ao afirmar que "muitas vezes não é o aluno que precisa de orientação psicológica, é a familia que precisa; às vezes é o pai, a mãe e isso acaba sendo despejado em cima do aluno".

Outro dado identificado refere-se ao fato de os educadores, em decorrência da inclusão do psicólogo na rede de saúde, contarem com essa possibilidade de encaminhamento dos pais para um atendimento, como afirma Amanda, professora há 12 anos após citar algumas queixas escolares:

Questão da violência, da agressividade de alguns pais. Questão das crianças que não aceitam se alimentar, ou que não aceitam se juntar ao grupo [...]. Elas são extremamente agressivas, e que, às vezes, num acompanhamento com as famílias, mas assim, num acompanhamento às vezes até através do posto de saúde em coletivo com a creche.

Além disso, o psicólogo é percebido como "alguém de fora" que poderia ser visto com mais respeito, podendo influenciar e intervir de maneira mais efetiva na família: "às vezes vindo uma pessoa de fora para estar junto, acompanhando, às vezes até mais respeitada, sabe lidar melhor com essas questões" (Amanda, professora há 12 anos). Ao encontro desta ideia, Bruna, professora de uma creche da rede pública, profissional da área há nove anos, concorda: "Acho que uma pessoa de fora, com outros conhecimentos, faria com que eles (os pais) dessem mais atenção". Esse dado mostra o quanto os profissionais da educação não estão preparados para lidar com as questões relativas ao processo de democratização do ensino que prevê a participação de toda a comunidade escolar nos processos educativos, necessitando de alguém "de fora" para auxiliá-los.

Portanto, as informações obtidas evidenciaram que os entrevistados, por vezes, acreditam que a família é a grande responsável pelos problemas escolares e o psicólogo deve atuar em específico nesse contexto. É importante destacar que a culpabilização da família pelo fracasso escolar está intimamente ligada aos conhecimentos que a própria psicologia produziu ao longo dos anos (Patto, 1999). Uma teoria, muito presente no Brasil na década de 70, refere-se à teoria da carência cultural. Conforme destaca Sawaya (2002), essa concepção é uma das responsáveis pela visão de que o aluno pobre não se alinha com a proposta escolar, desconsiderando, assim, a cultura popular. A escola pode ser observada como uma instituição orientada pela mesma lógica da sociedade de classes: as relações de poder então estabelecidas e constituem-se na violência presente na ideologia da escola como cultura dominante, ao desvalorizar a cultura popular (Angelucci,Kalmus, Paparelli,\& Patto, 2004; Thin, 2006). Esta ideologia resume-se em afirmar que o fracasso escolar dos alunos de camadas populares se dá devido à sua privação cultural resultante das más condições de vida, prejudicando, assim, o seu desenvolvimento cognitivo, psicomotor, perceptivo, afetivo, emocional e de linguagem (Sawaya, 2002).

Na obra "A produção do fracasso escolar: histórias de submissão e rebeldia" Patto (1999) faz uma crítica à teoria da carência cultural, a qual culpabiliza as famílias pelo fracasso escolar. Segundo a autora, ao se investigar o fracasso escolar não se pode isolá-lo de seus determinantes históricos e sociais. Além disso, temos que considerar as práticas escolares que o produzem bem como analisar a produção social de uma visão de mundo que legitima tais práticas.

Os dados da pesquisa, no que se refere à participação das famílias na escola, evidenciaram a necessidade de a psicologia desenvolver estratégias voltadas à ampliação da participação de toda a comunidade escolar na construção de processos educativos mais potencializadores de todos os envolvidos. Para tanto, urge a necessidade de se romper com explicações generalizantes acerca da (não) participação das famílias, buscando-se compreender cada caso a partir do contexto histórico e político. Desconstruir modelos que idealizam as famílias também é um grande desafio para auxiliar nos processos de gestão democrática, favorecedores da participação de todos.

\section{O psicólogo como um profissional que atua no diagnóstico e no atendimento individual dos "alunos-problema"}

Outra expectativa evidenciada nas falas dos entrevistados em relação ao papel do psicólogo diz respeito à compreensão de que seu trabalho deve ser focado no diagnóstico e tratamentode problemas individuais dos alunos. Esta visão considera que o fracasso escolar é resultado da falta de capacidade do aluno, sem levar em consideração o contexto social, político e econômico refletido na própria escola e nas práticas e ideologias dos profissionais da educação.

As falas dos entrevistados que reiteram esse eixo de análise apontam que há uma expectativa, por parte da escola, de que os alunos se adaptem aos procedimentos escolares. O depoimento de Mário, professor há 14 anos, é representativo desse entendimento.

\footnotetext{
Mas, como falei, temos pouco tempo pra traçar esse perfil, o do aluno que acaba não se enquadrando, né, na prática é isso, o aluno que não se enquadra. Torna-se muito difícil você trabalhar com ele, você não tem acompanhamento específico para ele, né?Isso falta mesmo.
} 
A fala acima evidencia o quanto se espera que os alunos se adaptem à escola, bem como a aposta de que algo ou alguém "de fora" resolva os problemas escolares. Ela evidencia também como o processo de pedagogização do conhecimento - o qual tem, como premissa central, a homogeneização e normalização dos sujeitos com base em padrões previamente definidos (Rocha, 2000) - está presente no âmbito escolar e opera como um elemento que exclui quem não se enquadra nesse padrão. Ou, nas palavras de Angelucci e cols. (2004, p. 60), "no interior de uma concepção de normalidade como adaptação, o não ajustamento à escola ou a insatisfação com características do ambiente escolar são incapacidade individual de orientar-se pelo princípio de realidade".

Quando os discursos dos educadores apontam apenas para os alunos, ao invés de considerarem as práticas que são desenvolvidas no âmbito da escola e as políticas educacionais, esses colaboram para a manutenção do sistema educacional da forma como está. Para ilustrar, pode-se destacar a fala de Murici, professora de uma escola da rede pública, profissional da educação há 29 anos, que, ao relatar as dificuldades que encontra na sala de aula, exemplifica com uma de suas turmas da manhã que, no geral, "é bastante indisciplinada. Tenho dificuldades com um aluno específico que apresenta problemas de comportamento".

A respeito do mesmo conteúdo da fala da professora Murici, Sayão e Guarido (2004) destacam que geralmente a busca pelos serviços do psicólogo na instituição escolar se dá quando há algum comportamento destoante do resto do grupo. Para desenvolver este assunto, as autoras expuseram uma pesquisa realizada em 1990 nas creches da USP, onde as professoras afirmavam ter extrema dificuldade em trabalhar com uma turma específica de crianças com idades entre quatro e cinco anos. Falas como "o trabalho não anda", "não consigo ficar com eles" ou "não sei como manter meu projeto" eram constantes entre as educadoras entrevistadas (Sayão, \& Guarido, 2004, p.84).

Outro elemento que corrobora o processo de culpabilização dos alunos pode ser identificado no relato acerca das reuniões do conselho de classe. Um depoimento representativo foi expresso por Clara, diretora de uma creche da rede pública, ao relatar que, a partir dessas reuniões, “(...) a gente encaminha para outros profissionais: se é problema de linguagem, encaminha para a fono; se é problema de comportamento, a gente acaba encaminhando para o psicólogo". Mattos (2005), ao pesquisar os conselhos de classe, também pôde identificar esse processo de culpabilização dos alunos. Segundo a autora, independentemente do seu objetivo mais amplo, a pauta normalmente se refere aos alunos e não ao trabalho dos educadores e à interação pedagógica. A autora observa ainda que as soluções para as queixas relatadas são buscadas fora da escola.

Considerando que o psicólogo já está inserido na equipe ampliada das unidades de saúde, alguns entrevistados têm buscado encaminhar as "crianças-problema". Vejamos o depoimento de Leonora, diretora e supervisora escolar que atua na educação há 17 anos: "Em relação aos alunos, a nossa postura é de encaminhar pro psicólogo ali do posto de saúde. Então alunos que apresentam qualquer problema psiquiátrico, de comportamento, nós encaminhamos ali pro psicólogo do posto de saúde".

Em seus estudos, Garrido e Moysés (2010) destacam que o discurso para naturalizar a desigualdade social encontra-se sustentado pelo argumento de que as diferenças individuais e biológicas são determinantes da exclusão social. Ao corroborar este discurso, a sociedade colabora para a manutenção das desigualdades sociais. "Aplicada à escola, essa concepção acarreta o entendimento de que as crianças recebem notas baixas por incapacidade de aprender" (Garrido, \& Moysés, 2010, p.149). A fala dos profissionais da educação, à vista disso, direcionando a responsabilidade do fracasso escolar para a criança, é mais um exemplo do discurso que justifica fatos políticos, econômicos e sociais a partir de uma visão medicalizante.

Nesta unidade de análise foram evidenciados os discursos que reiteram o papel do psicólogo como alguém qualificado para o encaminhamento das queixas escolares, sendo essas compreendidas em muitos casos a partir de uma perspectiva individualizante, patologizante e medicalizante. No próximo tópico, serão apresentados os discursos que corroboram a percepção do psicólogo como um profissional que atua na perspectiva da prevenção e da promoção de saúde na escola.

\section{O psicólogo como profissional da prevenção e da promoção de saúde}

Nesta categoria, destacam-se os discursos de educadores mais voltados à compreensão de que o psicólogo pode atuar na escola no âmbito da prevenção e da promoção de saúde. Esses discursos apontam que o psicólogo poderia orientar os educadores em relação ao trabalho pedagógico e proporcionar um ambiente de escuta e suporte emocional. Entende-se que a promoção de saúde define-se "[...] por uma visão sistêmica de saúde, compreendendo que fatores relacionados ao modo de vida dos homens estarão atuando de forma direta nas reais possibilidades de uma vida saudável ou não" (Contini, 2000, p. 47).

O viés presente nesta unidade temática se opõe à visão medicalizante apresentada anteriormente nas falas dos educadores e corrobora o conceito de promoção de saúde proposto por Contini (2000). Isso porque compreende as dificuldades escolares como produzidas nas relações das quais a equipe pedagógica faz parte e indica o psicólogo como um profissional que poderá atuar no acolhimento dos educadores e na qualificação dos processos educacionais.

Mário, professor há 14 anos, apresentou uma visão que leva em conta o âmbito político das relações didáticas. Nas suas palavras: "o modelo de escola que temos ainda é um modelo muito arcaico. Você em uma sala de aula, você tem um quadro, você tem um professor, livros e deu. Então, o modelo de trabalho teria que ser outro". Percebe-se, na fala do professor, uma crítica ao que está instituído e um 
clamor por uma forma diferente de organizar a escola, a qual rompesse com esse modelo atual que, com algumas pequenas diferenças, reproduz o modelo jesuíta de ensino (Varela, 2004).

Muitos entrevistados demonstraram a necessidade de haver um espaço de escuta em que pudessem obter um suporte emocional, assim como orientações em relação ao seu trabalho. José e Amanda, professores de escolas da rede pública há 15 e 12 anos, respectivamente, destacaram a dificuldade que encontram ao lidar com os problemas dos outros e com os seus próprios problemas nas relações dentro da instituição. Comentam que seria interessante se o psicólogo atuasse nesse sentido, em um ambiente de escuta, já que muitos de seus colegas estão ficando "doentes". Já em relação aos educadores que conseguem criar espaços de escuta, esses mostram a potência de tais momentos no acolhimento às dificuldades vivenciadas no cotidiano, conforme relato abaixo:

É no horário do café que se acaba trazendo problemas de sala e em momentos de reunião pedagógica e conselho de classe, né? A gente discute essas questões, essas questões de angústia, de desconforto em relação a problemas que a escola encontra cotidianamente (Leonora, diretora e supervisora escolar).

O depoimento acima mostra a importância de as instituições escolares fomentarem a criação de espaços que se caracterizem como lugar de escuta. "Tais espaços pretendem garantir a circulação dos discursos presentes na instituição, buscando a construção de outros novos, de forma a encontrar os significados dados àquilo que acontece no interior da instituição" (Sayão, \& Guarido, 2004, p.86). Além disso, as autoras acima destacam a relevância de a psicologia investir na produção de "novas significações para antigos fatos, sentido onde não existia algum, possibilidade de deslocamento das pessoas em seus lugares normalmente estabelecidos" (Sayão, \& Guarido, 2004, p.87).

Costa (2007) aponta a dificuldade da educação em recriar ao lidar com o novo, com o imprevisível, com as diferenças e multiplicidades presentes na atualidade. O mesmo autor corrobora a ideia de que tal comportamento se dá diante de alguns fatores: primeiro, porque os educadores se sentem preparados para lidar apenas com aquilo que já está instituído e normalizado; segundo, devido ao fato de estarem acostumados a pensar apenas por um viés, sem aceitar as contradições e as situações multilaterais. Assim, preserva-se o antigo e as alternativas pré-estabelecidas, fechando as portas para a invenção de novas possibilidades na educação.

Zanella e Molon (2007, p.264), ao estudarem os processos subjetivos que impedem a recriação de novos espaços nas instituições escolares, destacam que"nas escolas pulsam vidas que clamam por espaços de escuta e vazão para que possam eclodir. Pulsam desejos, recolhidos e abafados em razão das normas e ameaças de punição frequentes". As autoras acreditam que a vida presente nas relações e em seus sujeitos pode transformar a instituição ao abrir um espaço de invenção e não de aprisionamento. Nesse contexto, destacam a necessidade de as práticas do psicólogo estarem atentas às possibilidades de criação e (re)invenção dos espaços, das regras, das formas de ser, de falar e silenciar. Para tanto, o acolhimento à diversidade e o rompimento das cristalizações são questões importantes a serem observadas (Zanella,\&Molon, 2007).

Souza (2009), ao abordar a formação de professores, aponta que esta não se torna suficiente para atender à realidade e às demandas escolares atuais. Tal fator contribui para que o professor despreparado lide com uma rotina árdua e enfrente sua profissão como uma luta pela sobrevivência, não sobrando, assim, espaço para a pessoa do professor, suas reflexões e desejos. Por isso, Facci (2009) considera que "hoje, o professor está excluído da escola, ele não tem mais conseguido desempenhar sua função social: ensinar" (p. 115).

Em contraponto, quando há grupos de escuta, observa-se uma reorganização das relações na escola, como ilustra a fala da professora entrevistada Priscila:

Sim, a gente passou a conhecer também as outras pessoas que a gente não conhecia direito na correria do dia a dia, entendeu? As pessoas começaram também a trazer não só coisas da vida profissional, mas da vida pessoal também, então tu acabavas conhecendo um pouquinho de cada um, né? Foi bem legal, ajudava a compreender o outro.

O depoimento de Priscila reitera a premissa de que compreender a escola, portanto, não é buscar as carências ou internalizar a culpa no aluno, e sim buscar entender os processos institucionais geradores das dificuldades e do bom desempenho escolar (Sawaya, 2002).

A partir do momento em que espaços e reflexões são abertos na instituição de ensino, podem-se encontrar discursos como o da pedagoga Olívia: "Eu acho que o problema nunca é a criança, porque ela tá só se descobrindo, se conhecendo, ela tá só expressando o que estamos ensinando para ela".

Portanto, os discursos que compuseram essa unidade de análise apontaram uma compreensão das queixas escolares como produzidas nas relações estabelecidas no interior da escola. Além disso, ressaltaram a importância de a Psicologia contribuir com a realização de um trabalho pautado no acolhimento dos professores e mediação das dificuldades enfrentadas por eles no cotidiano da escola como importante para favorecer a emergência de processos educativos mais qualificados.

Todavia, com base em uma perspectiva crítica de atuação profissional em psicologia, cabe alertar para o risco de que, defendendo um trabalho a ser realizado somente com sujeitos da escola, sem analisar o contexto social e político que corrobora a produção do fracasso escolar, corre o risco de, ainda, individualizar o problema. Nesse sentido, destaca-se a importância de se considerar que a escola não é uma instituição isolada da sociedade e que os sujeitos da 
educação são atravessados e constituídos por determinantes de classe social, gênero, raça, deficiência, orientação sexual os quais, quando reproduzidos de forma acrítica, podem legitimar diversas formas de violência.

\section{Considerações Finais}

Esta pesquisa teve como objetivo principal identificar as necessidades de intervenção profissional em Psicologia Escolar na rede pública de ensino de uma capital do sul do Brasil. As informações obtidas contribuíram para delinear a formação dos psicólogos na universidade em que a pesquisa foi realizada e também ofereceram subsídios para o delineamento das ações de estágio supervisionado em psicologia escolar, aprimorando a articulação entre ensino, pesquisa e extensão.

Fica evidente, nas falas dos entrevistados, a relação que estabelecem entre a inclusão de psicólogos no contexto escolar e a constituição de espaço de expressão dos aspectos humanizantes e humanizadores presentes nas relações de ensino e aprendizagem e entre a escola e a sociedade. Paradoxalmente, esta expectativa se apresenta predominantemente a partir de uma perspectiva de cunho medicalizante de atuação do psicólogo. Nesta, os educadores compreendem as dificuldades escolares como dificuldades do aluno, tanto decorrentes da inadequação deles ao sistema escolar, como também de suas famílias, que apresentam dificuldades de propiciar condições de desenvolvimento satisfatórias ao bom aprendizado.

Essa redução da compreensão das dificuldades escolares a problemas dos alunos e de suas famílias (im) possibilita a emergência de um olhar ampliado no qual tais dificuldades são compreendidas considerando-se as relações sociais estabelecidas entre os diversos atores da escola e as questões referentes à política educacional brasileira. Concomitantemente às crenças biologizantes e patologizantes, constata-se a fragilidade da formação de professores no combate a esta lógica, aliada à sobrecarga de trabalho dos mesmos e à ausência de espaços de escuta e de articulação de mudanças em um contexto reflexivo e de acolhimento.

Ao encontrar diferentes discursos sobre a educação e o papel do psicólogo escolar, pôde-seperceber antigos obstáculos a enfrentar, velhas crenças intrínsecas na atualidade que ao mesmo tempo convivem com possibilidades de mudança. Diante disso, cabem alguns questionamentos: Como fazer com que os psicólogos sejam reconhecidos nas escolas como profissionais voltados à construção de processos educativos democráticos e potencializadores de todos os sujeitos, num momento em que cada vez mais ocorre a biologização e medicalização dos sujeitos? Como subverter as demandas medicalizantes de atuação profissional em psicologia? Como construir espaços de acolhimento e humanização das relações sociais constituídas na escola?

Não temos uma resposta para todas as questões acima. Todavia, acreditamos que uma estratégia importante refere-se à melhoria da formação inicial e continuada dos profissionais da educação. A psicologia escolar pode contribuir com essa estratégia mediando aapropriação crítica dos conhecimentos relativos à aprendizagem, ao desenvolvimento, às relações interpessoais e políticas educacionais. Além disso, o trabalho realizado junto aos professores deve ter como horizonte ético a garantia dos direitos humanos e valorização da diversidade.

No que se refere à formação do psicólogo, diante das demandas cada vez mais pautadas na biologização e medicalização dos fenômenos escolares, essa deve ser pautada também na apropriação crítica dos conhecimentos e políticas educacionais e em um compromisso ético-político com os sujeitos da educação. É importante que o psicólogo, ao se inserir no contexto educativo, tenha subsídios teórico-metodológicos para subverter os discursos que reduzem os fenômenos com que ele se depara no contexto escolar a questões individuais,bem como que desenvolva competências relacionais para agenciar sujeitos implicados com um processo educativo potencializador da diversidade de modos de ser e aprender.

\section{Referências}

Angelucci, C. B., Kalmus, J.,Paparelli, R.,\& Patto, M. H. S. (2004). O estado da arte da pesquisa sobre o fracasso escolar (19912002):um estudo introdutório Educação e Pesquisa, 30 (1), 51-72.

Antunes, M. A. M. (2008). Psicologia escolar e educacional: história, compromissos e perspectivas.Psicologia Escolar e Educacional, 12 (2), 469-475.

Bardin, L. (2000). Análise de Conteúdo. Lisboa: Edições 70.

Brasil. Ministério da Saúde. (2009). Secretaria de Atenção à Saúde. Departamento de Atenção Básica. Saúde na Escola. Brasília: Ministério da Saúde.

Cabral, E.,\&Sawaya, S. M. (2001). Concepção e atuação profissional diante das queixas escolares: os psicólogos nos serviços púbicos de saúde Estudos em Psicologia,6 (2), 143-155.

Chagas, J. C, Pedroza, R. L. S.,\& Branco, A. U. (2012). Direitos humanos e democracia na educação infantil: atuação do psicólogo escolar em uma associação pró-educação. Estudos de Psicologia, 17 (1), 73-81.

Contini, M. L. J. (2000). Discutindo o conceito de promoção de saúde no trabalho do psicólogo que atua na educação Psicologia Ciência e Profissão, 20 (2), 46-59.

Cord, D., Gesser, M., Nunes, A. S. B., \&Storti, M. M. T. (2015).As significações de profissionais que atuam no Programa Saúde na Escola (PSE) acerca das dificuldades de aprendizagem: patologização e medicalização do fracasso escolar. Texto não publicado. 
Costa, S. S. G. (2007). Educação, políticas de subjetivação e sociedades de controle. Em A. Marcondes, A. Fernandes,\& M. Rocha (Orgs.), Novos Possiveis no encontro da psicologia com a educação (pp. 15-35). São Paulo: Casa do Psicólogo.

Cruz Neto, O. (2000). O trabalho de campo como descoberta e criação. Em M. C. S. Minayo (Org.),Pesquisa social: teoria, método e criatividade. Petrópolis: Vozes.

Facci, M. G. D. (2009). Intervenção do psicólogo na formação de professores: contribuições da psicologia histórico-cutural. Em C. M. Marinho-Araujo (Org.) Psicologia escolar: novos cenários e contextos de pesquisa, formação e prática (pp. 107-131). Campinas-SP: Alínea.

Garrido, J.,\& Moysés, M. A. F. (2010). Um panorama nacional dos estudos sobre a medicalização da aprendizagem de crianças em idade escolar. Em Conselho Regional de Psicologia de São Paulo, \& Grupo Interinstitucional Queixa Escolar (Orgs.) Medicalização de crianças e adolescentes: conflitos silenciados pela redução de questões sociais a doenças de indivíduos (pp. 149-161). São Paulo: Casa do Psicólogo.

Gesser, M. (2013). Políticas públicas e direitos humanos: desafios à atuação do Psicólogo. Psicologia: ciência e profissão, 33 (spe), 66-77.

Guarido, R. (2010). A Biologização da vida e algumas implicações do discurso médico sobre a educação. Em Conselho Regional de Psicologia de São Paulo, \& Grupo Interinstitucional Queixa Escolar (Orgs.),Medicalização de crianças e adolescentes: conflitos silenciados pela redução de questões sociais a doenças de indivíduos (pp. 27-39). São Paulo: Casa do Psicólogo.

Machado, A. M. (2007). Plantão Institucional: um dispositivo criador. Em A. M. Machado, A. Fernandes,\& M. Rocha (Orgs) Novos Possíveis no encontro da Psicologia com a Educação (pp. 117145). São Paulo: Casa do Psicólogo.

Mattos, C. L. G. (2005). O conselho de classe e a construção do fracasso escolar. Educação e pesquisa, 31 (2), 215-228.

Meira, M. E. M. (2012). Para uma crítica da medicalização na educação. Revista Semestral da Associação Brasileira de Psicologia Escolar e Educacional,16(1), 136-142.

Meira, M. E. M. (2007). Psicologia histórico-cultural: Fundamentos, pressupostos e articulações com a Psicologia da Educação. Em M. E. M. Meira,\& M. G. D. Facci (Orgs.) Psicologia HistóricoCultural: Contribuições para o encontro entre a subjetividade e a educação (pp. 27-62). São Paulo: Casa do Psicólogo.

Meira, M. E. M. (2003). Construindo uma concepção crítica de Psicologia Escolar: contribuições da pedagogia histórico-crítica e da psicologia sócio-histórica. Em M. E. M. Meira,\& M. A. M. Antunes (Orgs.), Psicologia escolar: teorias críticas (pp. 13-73). São Paulo: Casa do Psicólogo. 2003.
Meira, M. E. M. (2000). Psicologia Escolar: pensamento crítico e práticas profissionais. Em E. R. Tanamachi, M. L. Rocha, \& M. Proença (Orgs) Psicologia e educação: desafios teórico-práticos (pp. 35-72). São Paulo: Casa do Psicólogo.

Minayo, M. C. de S. (2008). O desafio do conhecimento: pesquisa qualitativa em saúde ( $11^{\mathrm{a}}$ ed.). São Paulo: Hucitec.

Moysés, M. A. A,\& Collares, C. A. L. (2010). Dislexia e TDAH: uma análise a partir da ciência médica. Em Conselho Regional de Psicologia de São Paulo,\& Grupo Interinstitucional Queixa Escolar (Orgs.),Medicalização de crianças e adolescentes: conflitos silenciados pela redução de questões sociais a doenças de indivíduos(pp. 71-110).São Paulo: Casa do Psicólogo.

Patto, M. H. S. (1999). A produção do fracasso escolar. histórias de submissão e rebeldia ( $2^{\mathrm{a}}$ ed.). São Paulo: Casa do Psicólogo.

Patto, M. H. S. (2009). O que a história pode dizer sobre a profissão do psicólogo: a relação Psicologia-Educação. Em A. M. B. Bock (Org.), Psicologia e compromisso social (pp. 29-36). São Paulo: Cortez.

Rego, T. C. (2002). Configurações sociais e singularidades: o impacto da escola na constituição do sujeito. Em M. K. Oliveira, D. T. R. Souza,\& T. C. Rego (Orgs.), Psicologia, educação e temáticas da vida contemporânea (pp. 47-75). São Paulo: Moderna.

Ribeiro, D. F.,\& Andrade, A. S. (2006). A Assimetria na Relação Entre Família e Escola Pública. Paidéia,16(35), 385-394.

Rocha, M. L. (2000). Educação em tempos de tédio: um desafio a micropolítica. Em E. R. Tanamachi, M. L. da Rocha \& M. Proença (Orgs.), Psicologia e educação: desafios teórico-práticos (pp. 185207). São Paulo: Casa do Psicólogo.

Sayão, Y., \& Guarido, R. L. (2004). Intervenção psicológica em creche/pré-escola. Em A. M., Machado,\& M. P. R., Souza (Orgs.), Psicologia Escolar: Em busca de novos rumos (pp. 83-91). São Paulo: Casa do Psicólogo.

Sawaya, S. M. (2002). Novas perspectivas sobre o sucesso e o fracasso escolar. Em M. K. Oliveira, D. T. R. Souza,\& T. C. Rego (Orgs.), Psicologia, Educação e as temáticas da vida contemporânea (pp. 197-213). São Paulo: Moderna.

Souza, M. P. R. (2010). Retornando à patologia para justificar a não aprendizagem escolar: a medicalização e o diagnóstico de transtornos de aprendizagem em tempos de neoliberalismo. Em Conselho RegionaldePsicologia de São Paulo(Org.),Medicalização de crianças e adolescentes: conflitos silenciados pela redução de questões sociais a doenças de indivíduos (pp. 57-67). São Paulo: Casa do Psicólogo.

Souza, V. L. T. (2009). Educação, valores e formação de professores. Em C. M. Marinho-Araújo (Org.),Psicologia escolar. novos cenários e contextos de pesquisa, formação e prática (pp. 133151). Campinas: Alínea. 
Souza, M. P. R. (2004). A queixa escolar e o predomínio de uma visão de mundo. Em M. P. R. Souza,\& A. M. Machado (Orgs.) Psicologia escolar: em busca de novos rumos (pp. 19-37). São Paulo: Casa do Psicólogo.

Varela, J. (2004). O estatuto do saber pedagógico. Em T. T. Silva (Org.), O sujeito da educação: estudos foucaultianos (pp. 87-96). Petrópolis: Vozes.

Thin, D. (2006). Para uma análise das relações entre famílias populares e escola: confrontação entre lógicas Socializadoras. Revista Brasileira de Educação, 11 (32), 211-225.
Yamamoto, K., Santos, A. A. L., Galafassi, C., Pasqualini M. G.,\& Souza, M. P. R. (2013).Como atuam psicólogos na educação pública paulista? um estudo sobre suas práticas e concepções. Psicologia: Ciência e profissão, 33(4), 794-807. Disponível: http://dx.doi.org/10.1590/S1414-98932013000400003.

Zanella, A. \&Molon, S. I. (2007). Psicologia (em) contextos de escolarização formal: das práticas de dominação à (re)invenção da vida. Contrapontos, 7(2), 255-268.

\section{Sobre os autores}

Luísa Evangelista Vieira Prudêncio (luisa.evangelista.vp@gmil.com) Graduanda em Psicologia pela UFSC.

Marivete Gesser (marivete@yahoo.com.br)

Doutora em Psicologia pela UFSC.Centro de Filosofia e Ciências Humanas da Universidade Federal de Santa Catarina.

Leandro Castro Oltramari (leandrooltramari@gmail.com)

Doutor em Ciências Humanas pela UFSC, Centro de Filosofia e Ciências Humanas da Universidade Federal de Santa Catarina.

Denise Cord (cord.denise@gmail.com)

Doutora em Engenharia de Produção pela UFSC, Centro de Filosofia e Ciências Humanas da Universidade Federal de Santa Catarina. 